\title{
Evidence of Selection for Fungicide Resistance in Zymoseptoria tritici Populations on Wheat in Western Oregon
}

Laura E. Hayes and Kathryn E. Sackett, Department of Botany and Plant Pathology, Nicole P. Anderson and Michael D. Flowers, Department of Crop and Soil Science, and Christopher C. Mundt, Department of Botany and Plant Pathology, Oregon State University, Corvallis 97331

\begin{abstract}
Hayes, L. E., Sackett, K. E., Anderson, N. P., Flowers, M. D., and Mundt, C. C. 2016. Evidence of selection for fungicide resistance in Zymoseptoria tritici populations on wheat in western Oregon. Plant Dis. 100:483-489.

Plant pathogens pose a major challenge to maintaining food security in many parts of the world. Where major plant pathogens are fungal, fungicide resistance can often thwart regional control efforts. Zymoseptoria tritici, causal agent of Septoria tritici blotch, is a major fungal pathogen of wheat that has evolved resistance to chemical control products in four fungicide classes in Europe. Compared with Europe, however, fungicide use has been less and studies of fungicide resistance have been infrequent in North American Z. tritici populations. Here, we confirm first reports of $Z$. tritici fungicide resistance evolution in western Oregon through analysis of the effects of spray applications of propiconazole and an azoxystrobin + propiconazole mixture during a single growing season.

Frequencies of strobilurin-resistant isolates, quantified as proportions of G143A mutants, were significantly higher in azoxystrobin-sprayed plots compared with plots with no azoxystrobin treatment at two different locations and were significantly higher in plots of a moderately resistant cultivar than in plots of a susceptible cultivar. Thus, it appears that western Oregon Z. tritici populations have the potential to evolve levels of strobilurin resistance similar to those observed in Europe. Although the concentration of propiconazole required to reduce pathogen growth by $50 \%$ values were numerically greater for isolates collected from plots receiving propiconazole than in control plots, this effect was not significant $(P>0.05)$
\end{abstract}

Fungicides play a significant role in crop production and in attaining food security (Berry et al. 2008; Cooper and Dobson 2007; Edwards-Jones 2008; Ragsdale and Sisler 1994). Challenges associated with such chemical control of disease include economic and environmental costs (Pimentel 2005; Tilman et al. 2001; Wilson and Tisdell 2001), as well as an increasing rate of resistance to fungicides in plant pathogen populations (Brent and Hollomon 2007; Deising et al. 2008; Hewitt 1998; Ma and Michailides 2005; Sierotzki and Scalliet 2013; Urech et al. 1997). Fungicide usage patterns, as well as criteria for selection of crops for fungicide application, are dynamic (Morton and Staub 2008; Russell 2005). For example, use of fungicides on cereals is a relatively recent phenomenon, driven greatly by intensification of cereal production in Europe. By 2005, global fungicide use on cereals became equal to that of fruit and vegetable crops (Morton and Staub 2008).

In Europe, Septoria tritici blotch (STB), caused by Zymoseptoria tritici (synonym Mycosphaerella graminicola), has been the most important disease of wheat (Triticum aestivum) in recent decades (Bearchell et al. 2005). Common practice has been to make two to four applications per year of fungicide mixtures (Fraaije et al. 2012). A result of this heavy use of fungicide has been development of resistance against benzimidazole fungicides and quinone outside inhibitors (QoI or strobilurins) (Fraaije et al. 2012). Z. tritici isolates resistant to the most recently available fungicide class, the succinate dehydrogenase inhibitors (SDHI), have recently been found in both laboratory and field isolates of Z. tritici (Sierotzki and

Current address of L. E. Hayes: Health Statistics \& Surveillance Section, Connecticut Department of Public Health, Hartford, CT 06134.

Corresponding author: L. E. Hayes; E-mail; laura.hayes@ct.gov

Accepted for publication 12 July 2015.

http://dx.doi.org/10.1094/PDIS-02-15-0214-RE

(C) 2016 The American Phytopathological Society
Scalliet 2013), suggesting that resistance may be developing to this relatively new fungicide class. At present, chemical control of STB in Europe depends on use of demethylation inhibiting (DMI or azole) fungicides and the multisite inhibitor chlorothalonil (Fraaije et al. 2012). Though resistance to several azole fungicides has developed in Z. tritici populations, this chemical class has remained useful for two reasons: a slower rate of evolution of resistance (likely owing to the multiple-mutation nature of resistance to azoles), and incomplete cross-resistance among azoles (which has allowed for continual release and effective use of different azole fungicides) (Cools and Fraaije 2013).

The maritime climate in the Willamette Valley of Oregon is highly conducive to STB (Mundt et al. 1999). Fungicide use against STB in the Willamette Valley began in the early to mid-1980s. Resistance to the fungicide benomyl developed quickly (NSF Center for Integrated Pest Management 1999), prompting it to be replaced by propiconazole in the late 1980s to early 1990s. By the early 1990s, approximately one-half of commercial fields were sprayed, usually with a single application of propiconazole at flag leaf emergence. By the late 1990s, most fields received a single application of propiconazole yearly, and other azoles such as tebuconazole became available (C. C. Mundt, unpublished). The first strobilurin fungicide was registered in Oregon in 2000 (Pscheidt and Ocamb 2000), and blended products combining an azole and a strobilurin became popular soon after (C. C. Mundt, unpublished). A major change occurred in the mid-2000s with the introduction of new, aggressive races of wheat stripe rust, caused by Puccinia striiformis (Hovmøller et al. 2008; Milus et al. 2009). Since that time, two to four applications of fungicide per year have become the norm (C. C. Mundt, unpublished).

Though the recently increased use of fungicide on wheat in the Willamette Valley was targeted more against stripe rust than against STB, local Z. tritici populations were exposed to those same applications. Based on European experience with fungicide resistance in $Z$. tritici and the very high evolutionary potential of $Z$. tritici in the Willamette Valley (Mundt et al. 1999), we became concerned about the potential for development of fungicide resistance in this pathogen. As a result, we sampled $Z$. tritici from fungicide timing trials at two locations in 2012: a commercial farm in an area of intensive 
cereal production and an experimental farm with less cereal production in the surrounding area. These isolates provided evidence for the first discovery of resistance to strobilurin fungicides for Z. tritici in North America (Estep et al. 2013), and allowed for the molecular identification of mutations previously associated with resistance to both strobilurin and azole fungicides (Estep et al. 2015). This article describes the selective response of $Z$. tritici to applications of different fungicide treatments within a single growing season.

\section{Materials and Methods}

Experimental design. The data for this study originated from a 2012 fungicide timing trial in the Willamette Valley of western Oregon. We collected leaf samples from two of the sites where the trial was conducted: the Hyslop Crop Science Field Research

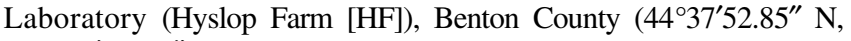
$\left.123^{\circ} 11^{\prime} 55.19^{\prime \prime} \mathrm{W}\right)$ and the North Valley Farm (NVF), Washington County $\left(45^{\circ} 33^{\prime} 58.53^{\prime \prime} \mathrm{N}, 123^{\circ} 00^{\prime} 11.78^{\prime \prime} \mathrm{W}\right)$. Wheat production on the HF consists mostly of unsprayed breeding plots, and is located in Benton County, which produced 3,642 ha of winter wheat the previous season (USDA NASS 2013). The NV experiment was conducted in a commercial wheat field in Washington County, which produced 6,070 ha of winter wheat the previous season (USDA NASS 2013). A split-plot design was used for the experiment, with four replicates at each field. Ten fungicide spray treatments were randomly assigned to 4.6-by-6.1-m main plots. Each main plot consisted of three 1.5-by-6.1-m subplots, each planted with one of three cultivars, varying in susceptibility to STB. Replicate blocks were separated along the plots' long edges by a 1.5-m buffer of 'Skiles' wheat. The short edges of the plots were mowed midseason, for a final plot length of $4.3 \mathrm{~m}$. The inoculum for secondary cycles of $Z$. tritici (pycnidiospores) is splash dispersed (King et al. 1983), which greatly reduces the potential for spread of the pathogen among experimental plots (Chen et al. 1994; McDonald and Martinez 1990). Fields were planted for the experiment on 13 October (HF) and 19 October (NVF) 2012.

For the purposes of this study, two of the 10 fungicide treatments, as well as the unsprayed control, were of interest: propiconazole (as Tilt at 0.12 liter active ingredient [a.i.] $\mathrm{ha}^{-1}$ ) and propiconazole + azoxystrobin mixture (azoxystrobin at 0.14 liter a.i. $\mathrm{ha}^{-1}$ and propiconazole as Quilt Xcel at 0.12 liter a.i. ha ${ }^{-1}$ ). Each fungicide treatment entailed application of the fungicides to the plots, once at Feekes 6 (23 to 24 March 2012) and again at Feekes 8 to 9 (9 to 10 May 2012) using a backpack sprayer (140 liter ha ${ }^{-1}$ spray volume and $0.14 \mathrm{MPa}$ spray pressure). The other fungicide treatments involved different frequencies and timings of strobilurin and azole fungicides. We further restricted our study to two of the three cultivars planted in the experiment: 'Tubbs06' (susceptible to STB) and 'Bobtail' (moderately resistant to STB).

Data collection. Fungal isolate acquisition and preparation. We collected flag leaves from wheat plants that had STB lesions, taking a total of 20 infected leaves per plot during each sampling period. These flag leaves originated from two adjacent plants at each of 10 sampling points located approximately $0.7 \mathrm{~m}$ apart along a V-shaped transect within each plot. We collected leaves from control plots twice, once between 14 and 15 April 2012 and again between 27 and 29 June 2012, with the latter collection period occurring 49 to 52 days after the second fungicide applications had been made to the sprayed plots. Flag leaves from fungicide-treated plots were collected only once, on the same day as the second collections from control plots. Flag leaves were dried and stored at $4{ }^{\circ} \mathrm{C}$ in a low-humidity cold room so that we could later isolate and evaluate lines of $Z$. tritici for fungicide resistance in the laboratory. We harvested spores from individual pycnidia by placing the preserved leaves overnight in petri dishes with moistened filter paper. The next morning, cirrhi (extruded pycnidiospores), were transferred with sterile forceps to a yeast malt agar ( $4 \mathrm{~g}$ of yeast extract, $4 \mathrm{~g}$ of malt extract, $4 \mathrm{~g}$ of sucrose, and $15 \mathrm{~g}$ of agar in 1 liter of water) plate amended with gentamicin $(10 \mathrm{ml} /$ liter) to prevent bacterial growth.
Propiconazole resistance assays. We assessed propiconazole resistance in the field-collected isolates by estimating the propiconazole concentration required to reduce pathogen growth by $50 \%$ $\left(\mathrm{EC}_{50}\right)$ in potato dextrose broth (PDB) in microtiter plate wells, generally following the approach of Beyer et al. (2011).

Briefly, spore isolates were grown in microtiter plate wells, each containing $75 \mu$ l of PDB ( $24 \mathrm{~g}$ of potato dextrose broth powder in 1 liter of water), $75 \mu$ of spores suspended in sterile deionized water (concentration $5 \times 10^{5}$ spores $/ \mathrm{ml}$ ), plus 1 of 12 concentrations of propiconazole (Syngenta, 95\% purity). Propiconazole concentrations (obtained via serial dilutions with 95\% ethanol) were $1250,250,50,10,2,0.4,0.08,0.016,0.0032,0.00064$, 0.000128 , and $0 \mathrm{mg} / \mathrm{liter}$. Propiconazole dilutions were added to microtiter plate wells, and the ethanol was allowed to evaporate in a sterile laminar flow hood prior to addition of the broth and spore suspensions.

Each 96-well plate was loaded with seven isolates, plus a blank PDB control. For each assay, three identical replicate plates were created. Plates were then covered with lids, sealed with Parafilm, and incubated in the dark at $22^{\circ} \mathrm{C}$ on a microplate shaker (VWR, orbit size $3 \mathrm{~mm}$ ) at $250 \mathrm{rpm}$. After 5 days, optical density (absorbance) at $595 \mathrm{~nm}$ was measured (Spectra MAX 190 Microplate Spectrophotometer; Molecular Devices).

Optical densities were averaged over replicates, then normalized by dividing by the optical densities of the fungicide control wells (cultures with propiconazole at $0 \mathrm{mg} / \mathrm{liter}$ ) after subtracting optical densities of PDB control wells (also averaged over replicates). $\mathrm{EC}_{50}$ values were calculated by fitting a self-starting nonlinear asymptotic model (i.e., the SSasymp function in the R stats package) to these data ( $R$ Core Team 2013). For each isolate, the $\mathrm{EC}_{50}$ was the fungicide concentration at which the optical densities of the spore cultures were half that of the cultures with no fungicide. $\mathrm{EC}_{50}$ values were estimated for up to five isolates from each subplot, each isolate originating from a different within-plot location.

Strobilurin resistance assays. We ran polymerase chain reaction restriction fragment length polymorphism (PCR-RFLP) on isolates from which we had obtained estimates of propiconazole resistance to classify them as either G143A mutants or wild types. The G143A mutation is associated with strobilurin resistance in Z. tritici (Estep et al. 2015; Fraaije et al. 2005; Torriani et al. 2008). PCRRFLP followed standard protocols specifically applied to the G143A mutation (Torriani et al. 2008), and laboratory methods have been described previously (Estep et al. 2015).

Statistical analyses. The mean $\mathrm{EC}_{50}$ and $\mathrm{G} 143 \mathrm{~A}$ mutation frequency were calculated for each plot. Hereafter, we refer to the mean $\mathrm{EC}_{50}$ values of isolates within a plot as the plot-averaged $\mathrm{EC}_{50}$ values. Results calculated from fewer than three isolates per plot were discarded. G143A mutant frequencies and plot-averaged $\mathrm{EC}_{50}$ calculations were based on a mean of 4.59 (standard deviation $[\mathrm{SD}]=0.73$, minimum $=3$, maximum $=5, n=58)$ and $4.57(\mathrm{SD}=$ 0.73 , minimum $=3$, maximum $=5, n=58$ ) isolates per plot, respectively.

We used linear mixed-effect modeling to identify the influences of spray treatment and collection timing, cultivar, and field site on the two outcome variables. $\mathrm{EC}_{50}$ data were $\ln$ transformed prior to analysis. G143A mutation frequencies were arcsine-square root transformed in accordance with normality assumption for residuals in general linear mixed modeling. We specified models for each outcome using the MIXED procedure in the SAS statistical software program (SAS Institute 2008). Full models for both outcomes included seven fixed effects: cultivar, field, and spray treatment and collection timing (hereafter referred to simply as "treatment") main effects, and cultivar-treatment, field-treatment, field-cultivar, and cultivar-treatment-field interactions (Federer and King 2007). Replicate and the replicate-treatment interaction (both nested within field) were random effects. $F$ tests of the homogeneity of variances based on full, fixed-effect models specific to each field site indicated that experiment results could be combined across fields for each outcome (propiconazole $\mathrm{EC}_{50}$ model: 
Table 1. Summary statistics for two fungicide resistance parameters, plot-averaged propiconazole concentration required to reduce pathogen growth by $50 \%$ $\left(\mathrm{EC}_{50}\right)$ and G143A mutant frequency (prior to statistical transformation), of Zymoseptoria tritici populations growing in experimental wheat plots in two fields in Oregon subjected to different fungicide spray regimes in $2012^{\mathrm{a}}$

\begin{tabular}{|c|c|c|c|c|c|c|c|c|}
\hline \multirow[b]{2}{*}{ Variable, cultivar } & \multicolumn{4}{|c|}{ North Valley Farm } & \multicolumn{4}{|c|}{ Hyslop Farm } \\
\hline & Early cont & Late cont & Late prop & Late prop + azo & Early cont & Late cont & Late prop & Late prop + azo \\
\hline \multicolumn{9}{|l|}{ Propiconazole $\mathrm{EC}_{50}$} \\
\hline \multicolumn{9}{|l|}{ Bobtail (mg/liter) } \\
\hline Mean & 0.108 & 0.097 & 0.221 & 0.217 & 0.091 & 0.136 & 0.185 & 0.128 \\
\hline Standard deviation & 0.040 & 0.031 & 0.246 & 0.170 & 0.056 & 0.100 & 0.060 & 0.146 \\
\hline Minimum & 0.056 & 0.056 & 0.066 & 0.089 & 0.035 & 0.048 & 0.097 & 0.025 \\
\hline Maximum & 0.151 & 0.126 & 0.585 & 0.468 & 0.157 & 0.279 & 0.235 & 0.231 \\
\hline Number of plots & 4 & 4 & 4 & 4 & 4 & 4 & 4 & 2 \\
\hline \multicolumn{9}{|l|}{ Tubbs 06 (mg/liter) } \\
\hline Mean & 0.073 & 0.076 & 0.211 & 0.196 & 0.095 & 0.112 & 0.140 & 0.129 \\
\hline Standard deviation & 0.038 & 0.021 & 0.173 & 0.083 & 0.039 & 0.062 & 0.045 & 0.011 \\
\hline Minimum & 0.040 & 0.058 & 0.069 & 0.100 & 0.065 & 0.069 & 0.095 & 0.121 \\
\hline Maximum & 0.125 & 0.107 & 0.421 & 0.300 & 0.149 & 0.156 & 0.194 & 0.137 \\
\hline Number of plots & 4 & 4 & 4 & 4 & 4 & 2 & 4 & 2 \\
\hline \multicolumn{9}{|l|}{ G143A frequency } \\
\hline \multicolumn{9}{|l|}{ Bobtail } \\
\hline Mean & 0.750 & 0.900 & 1.000 & 1.000 & 0.050 & 0.000 & 0.100 & 0.400 \\
\hline Standard deviation & 0.300 & 0.115 & 0.000 & 0.000 & 0.100 & 0.000 & 0.115 & 0.283 \\
\hline Minimum & 0.400 & 0.800 & 1.000 & 1.000 & 0.000 & 0.000 & 0.000 & 0.200 \\
\hline Maximum & 1.000 & 1.000 & 1.000 & 1.000 & 0.200 & 0.000 & 0.200 & 0.600 \\
\hline Number of plots & 4 & 4 & 4 & 4 & 4 & 4 & 4 & 2 \\
\hline \multicolumn{9}{|l|}{ Tubbs 06} \\
\hline Mean & 0.500 & 0.783 & 0.888 & 1.000 & 0.113 & 0.000 & 0.063 & 0.200 \\
\hline Standard deviation & 0.115 & 0.158 & 0.131 & 0.000 & 0.131 & 0.000 & 0.125 & 0.283 \\
\hline Minimum & 0.400 & 0.667 & 0.750 & 1.000 & 0.000 & 0.000 & 0.000 & 0.000 \\
\hline Maximum & 0.600 & 1.000 & 1.000 & 1.000 & 0.250 & 0.000 & 0.250 & 0.400 \\
\hline Number of plots & 4 & 4 & 4 & 4 & 4 & 2 & 4 & 2 \\
\hline
\end{tabular}

a Abbreviations: cont $=$ control, prop $=$ propiconazole, and azo $=$ azoxystrobin.

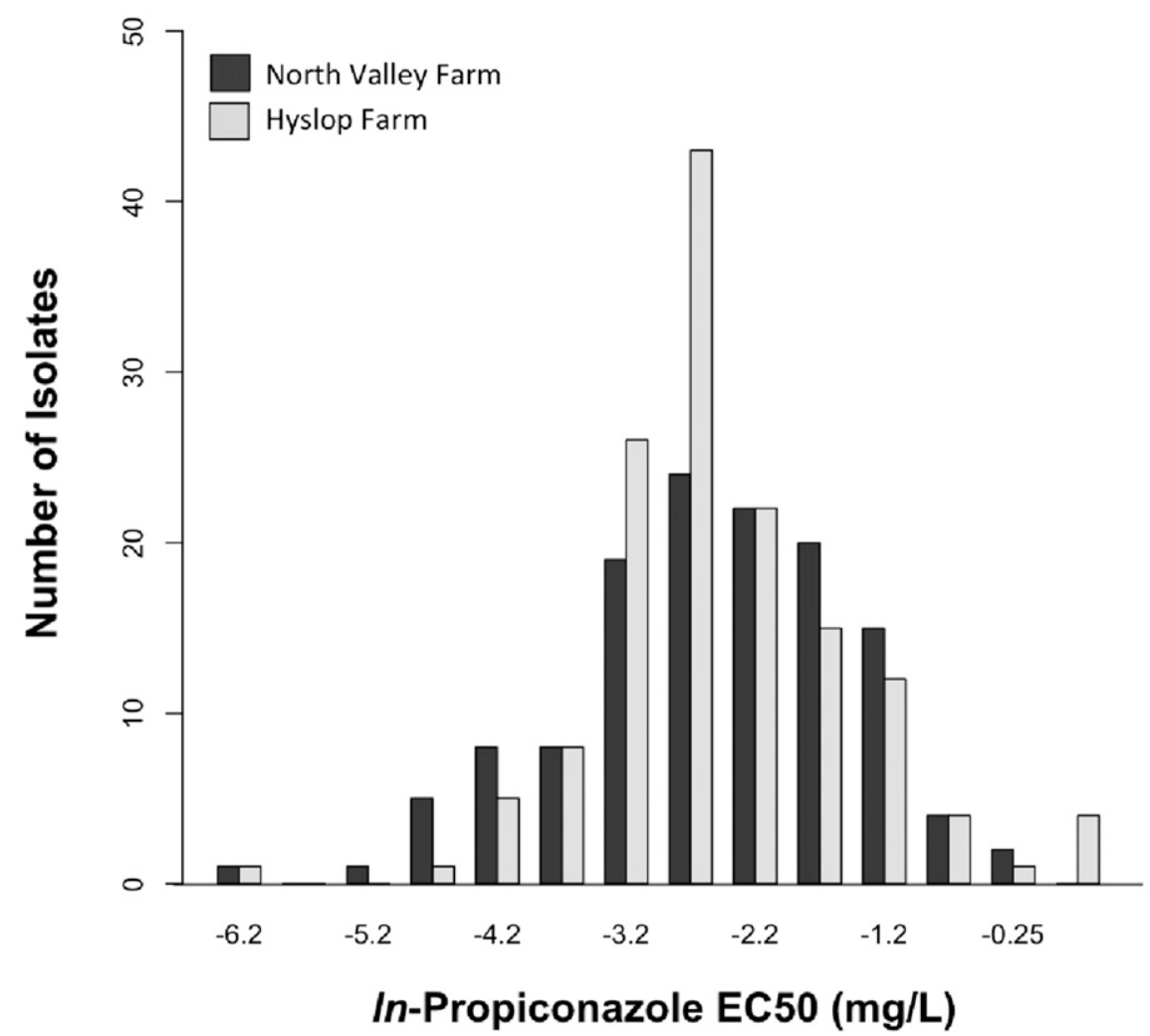

Fig. 1. Frequencies of In-transformed propiconazole concentration required to reduce pathogen growth by $50 \%$ (EC 50 ) values associated with Zymoseptoria tritici isolates originating from experimental wheat plots of at two sites in western Oregon in 2012: Hyslop Farm (Benton County) and North Valley Farm (Washington County). 
$P=0.760 ;$ G143A frequency model: $P=0.771)$. When there was a significant effect of treatment on a fungicide resistance outcome, we used Fisher's protected least squares difference (LSD) test to identify differences between treatments $(\alpha=0.05)$.
Additionally, we compared the $\ln$-transformed propiconazole $\mathrm{EC}_{50}$ values of isolates with the G143A mutation to those of wildtype isolates with a $t$ test, using isolates from control plots at both field sites to examine potential interactions between the two types of fungicide resistance considered in the study.
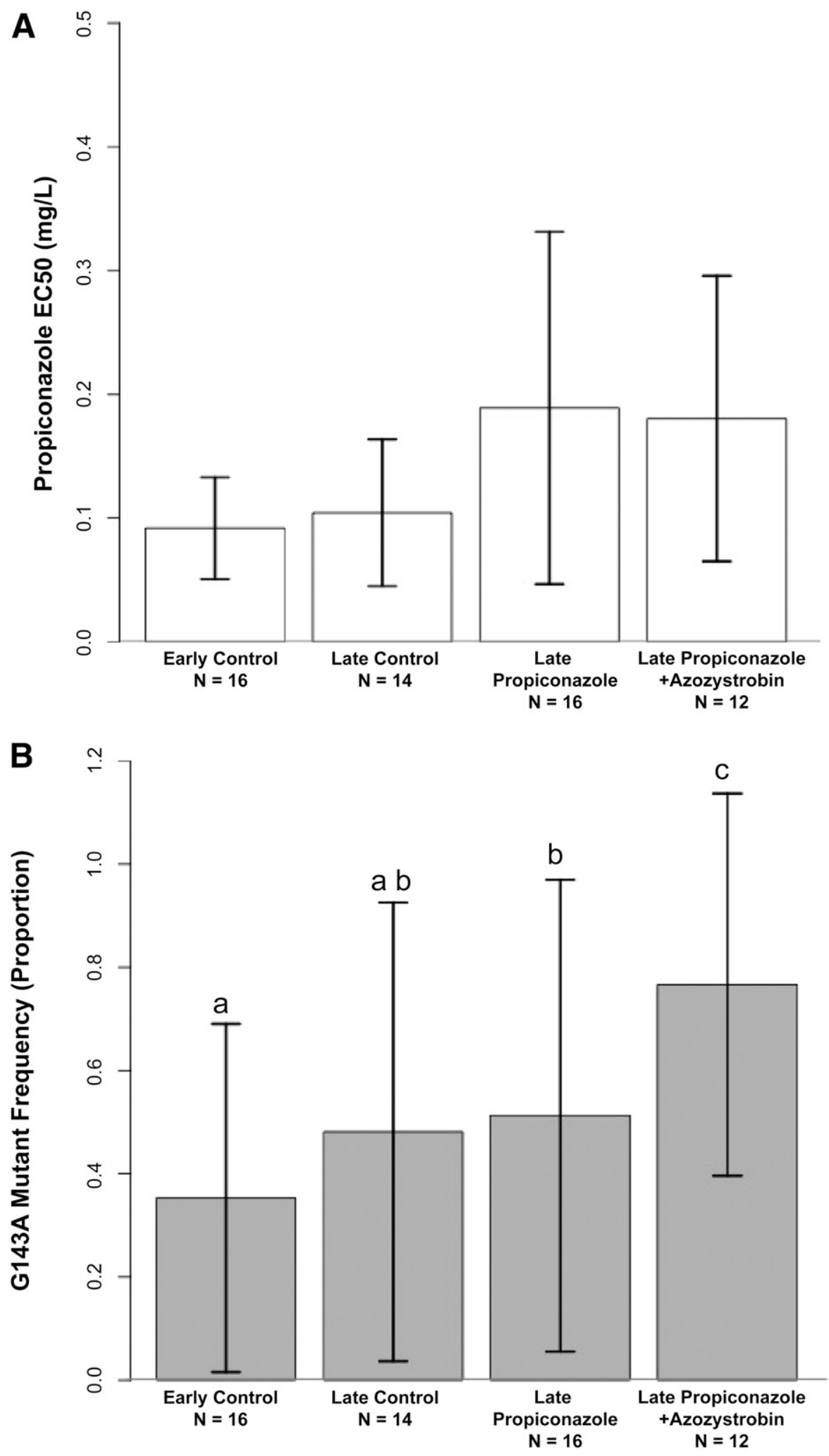

Fig. 2. A, Mean plot-averaged propiconazole concentration required to reduce pathogen growth by $50 \%$ ( $\left.E C_{50}\right)$ values of Zymoseptoria tritici isolates and $B$, mean proportions of $Z$. tritici isolates with the G143A mutation (G143A mutant frequency) from experimental wheat plots in two locations in westem Oregon in 2012: Hyslop Farm (Benton County) and North Valley Farm (Washington County). Fungicide applications (either propiconazole or propiconazole + azoxystrobin) were made twice on treatment plots, once in March and again in May 2012. "Early" in the $x$-axis legend refers to isolates collected 14 to 15 April 2012 and "Late" refers to collections made during 27 to 29 June 2012. Emor bars represent standard deviations. Identical letters over bars indicate that the outcome variable for different treatments and sampling periods did not differ significantly based on Fisher's protected least squares difference test. 


\section{Results}

The mean plot-averaged $\mathrm{EC}_{50}$ of isolates and the frequency of the G143A mutation varied among treatments, cultivars, and locations (Table 1; Fig. 1). Overall, $\mathrm{EC}_{50}$ values averaged $0.137 \mathrm{mg} / \mathrm{liter}$ $(\mathrm{SD}=0.198$, minimum $=0.002$, maximum $=1.632, n=271)$ and the G143A mutation was present in 134 of the 272 isolates (49.2\%) used in the analyses.

Propiconazole-treated plots had the highest plot-averaged propiconazole $\mathrm{EC}_{50}$ values (mean $=0.189 \mathrm{mg} / \mathrm{liter}, \mathrm{SD}=0.142, n=16$ ), followed by propiconazole + azoxystrobin-treated plots $($ mean $=$ $0.181 \mathrm{mg} /$ liter, $\mathrm{SD}=0.115, n=12$ ), late-sampled control plots (mean $=0.104 \mathrm{mg} /$ liter, $\mathrm{SD}=0.593, n=14)$, and early-sampled control plots (mean $=0.092 \mathrm{mg} / \mathrm{liter}, \mathrm{SD}=0.041, n=16$ ) (Fig. 2). Plotaveraged propiconazole $\mathrm{EC}_{50}$ values associated with the moderately disease-resistant Bobtail (mean $=0.149 \mathrm{mg} / \mathrm{liter}, \mathrm{SD}=0.121, n=30$ ) were higher than those of the susceptible Tubbs06 (mean = $0.130 \mathrm{mg} / \mathrm{liter}, \mathrm{SD}=0.087, n=28)$. NVF had higher plotaveraged propiconazole $\mathrm{EC}_{50}$ values (mean $=0.150 \mathrm{mg} / \mathrm{liter}, \mathrm{SD}=$ $0.129, n=32$ ) than HF (mean $=0.128 \mathrm{mg} / \mathrm{liter}, \mathrm{SD}=0.066, n=$ 26). However, none of these differences between means were statistically significant, because results from the full $\mathrm{EC}_{50}$ model indicated no significant effects of treatment, cultivar, or field $(P=0.115,0.842$, and 0.710 , respectively) or significant interactions (treatment-cultivar: $P=0.735$, treatment-field: $P=0.547$, field-cultivar: $P=0.437$, and treatment-field-cultivar: $P=0.635$ ) (Table 2).

Analysis of the G143A frequency data, on the other hand, showed a significant influence of treatment $(P=0.010)$, cultivar $(P=0.047)$, and field $(P<0.001)$ (Table 2$)$. Propiconazole + azoxystrobin-treated plots had the highest G143A frequencies (mean $=0.767, \mathrm{SD}=0.370$, $n=12$ ), followed by propiconazole-treated plots (mean $=0.513, \mathrm{SD}=$ $0.458, n=16$ ), late-sampled control plots (mean $=0.481, \mathrm{SD}=$ $0.445, n=14$ ), and early-sampled control plots (mean $=0.353, \mathrm{SD}=$ $0.337, n=16$ ) (Fig. 2). LSD tests indicated that early-sampled control plots had lower G143A mutation frequencies than both the propiconazole- and propiconazole + azoxystrobin-treated plots $(P=$ 0.017 and $P<0.001$, respectively), late-sampled control plots had lower G143A frequencies than propiconazole + azoxystrobintreated plots $(P<0.001)$, and propiconazole-treated plots had lower G143A frequencies than plots treated with propiconazole + azoxystrobin $(P=0.034)$. G143A frequencies associated with the moderately disease-resistant Bobtail (mean $=0.533, \mathrm{SD}=0.447, n=30$ ) were higher than those of the susceptible Tubbs06 (mean $=0.492$, SD $=0.400, n=28)$. G143A frequencies of plots at NVF were higher (mean $=0.853, \mathrm{SD}=0.206, n=32)$ than those at HF (mean $=$ $0.096, \mathrm{SD}=0.156, n=26$ ). No interactions in the full G143A frequency model were statistically significant (treatment-cultivar: $P=$ 0.975, treatment-field: $P=0.064$, field-cultivar: $P=336$, and treatment-field-cultivar: $P=0.216$; Table 2 ).

Patterns of the magnitudes of both outcome variables according to treatment when mean $\mathrm{EC}_{50}$ and overall G143A frequency were calculated across all isolates were the same as patterns of mean plotaveraged $\mathrm{EC}_{50}$ values and G143A frequencies (Figs. 2 and 3). Isolates with the G143A mutation collected from control plots had no significant difference in propiconazole $\mathrm{EC}_{50}$ values (mean = $0.110 \mathrm{mg} / \mathrm{liter}, \mathrm{SD}=0.090, n=55$ ) compared with wild-type isolates from control plots $($ mean $=0.101 \mathrm{mg} / \mathrm{liter}, \mathrm{SD}=0.107, n=84)(t=$ -0.357 , df $=119.02, P=0.722$ ).

\section{Discussion}

Results of this study show that selection for increased frequency of resistance to strobilurins conferred by the G143A mutation occurred over the course of a single growing season in western Oregon populations of $Z$. tritici. Combined with a study of fungicide resistance gene sequence evolution in the same region over a 20 -year period (Estep et al. 2013, 2015), these results suggest that the Willamette Valley is an active site of the evolution of resistance to strobilurins and azoles in Z. tritici. Moreover, they suggest that selection for resistance occurs on a relatively short time-scale and is highly local. This result is not surprising, given heavy fungicide use in the Willamette Valley and evidence from this pathosystem in Europe, as well as from other fungal systems, for rapid selection for resistance following heavy fungicide use (Cools and Fraaije 2013; Fraaije et al. 2012; Gisi et al. 2002; Sierotzki and Scalliet 2013) (C. C. Mundt, unpublished). Continued application of these fungicides could lead to a greater need for alternative control measures of STB in the Willamette Valley, including use of resistant cultivars, as the frequency of fungicide resistance increases. Indeed, a recent survey indicated that the early-season frequency of strobilurin-resistant isolates at the HF site had increased to approximately $70 \%$ by 2014 (C. H. Hagerty, K. E. Sackett, and C. C. Mundt, unpublished).

Evidence in support of increased resistance to one of the fungicides in this study, azoxystrobin, indicated that G143A frequencies were higher in plots treated with the azoxystrobin + propiconazole mixture compared with control (nonsprayed) plots, both early and late in the seasons. This within-season selection of strobilurin resistance in western Oregon Z. tritici populations is consistent with results of similar experiments conducted in Northern Ireland (McCartney et al. 2007). Similarity of results between studies in geographic regions is not surprising, given the near complete resistance to strobilurins (and, thus, strong selective advantage in areas where strobilurins are used) associated with the G143A mutation (Gisi et al. 2002; Torriani et al. 2008). Introduction of resistance-conferring alleles in local Z. tritici populations is plausible through migration or de novo mutations in European populations. De novo mutation appears to be responsible for emergence of G143A in both Europe (Torriani et al. 2009) and Oregon (Estep et al. 2015), such that a mechanism of mutant introduction and selective pressure for fixation following introduction are both present in the Oregon $Z$. tritici population.

Some evidence for the occurrence of increased azole resistance in $Z$. tritici populations over the course of a single growing season emerged from this study. Notably, the highest observed $\mathrm{EC}_{50}$ values among treatments were those that occurred in the two groups exposed to propiconazole. Given that azoles are regularly used by farmers in this region to control wheat disease (M. Flowers, N. P. Anderson, and C. C. Mundt, personal communication), as well as recent findings in Europe of lower levels of control achieved by azoles and lowered isolate sensitivity to azoles compared with historic ones (Brunner et al. 2008; Cools and Fraaije 2013), further monitoring of azole sensitivity in the Willamette Valley region is warranted. In this study, there also was a numerically higher propiconazole $\mathrm{EC}_{50}$ detected among isolates

Table 2. Results of mixed modeling of two fungicide resistance parameters, plot-averaged propiconazole concentration required to reduce pathogen growth by $50 \%\left(\mathrm{EC}_{50}\right)$ and $\mathrm{G} 143 \mathrm{~A}$ mutant frequency, of Zymoseptoria tritici populations growing in experimental wheat plots, modeled as a function of the fixed effects fungicide application treatment, field of study, and wheat cultivar, and a random effect for replicate ${ }^{\mathrm{a}}$

\begin{tabular}{lccrr}
\hline $\begin{array}{l}\text { Dependent variable, } \\
\text { source of variation }\end{array}$ & $\begin{array}{c}\text { Numerator } \\
\text { DF }\end{array}$ & $\begin{array}{c}\text { Denominator } \\
\text { DF }\end{array}$ & $\begin{array}{c}\boldsymbol{F} \\
\text { statistic }\end{array}$ & $\begin{array}{c}\boldsymbol{P} \\
\text { value }\end{array}$ \\
\hline Propiconazole EC 50 & & & & \\
Treatment & 3 & 16 & 2.32 & 0.115 \\
Cultivar & 1 & 20 & 0.04 & 0.842 \\
Field & 1 & 6 & 0.15 & 0.710 \\
Treatment $\times$ cultivar & 3 & 20 & 0.43 & 0.735 \\
Treatment $\times$ field & 3 & 16 & 0.73 & 0.547 \\
Field $\times$ cultivar & 1 & 20 & 0.63 & 0.437 \\
Treatment $\times$ field $\times$ & 3 & 20 & 0.58 & 0.635 \\
$\quad$ cultivar & & & & \\
G143A frequency & & 16 & 8.95 & 0.010 \\
Treatment & 3 & 20 & 4.47 & 0.047 \\
Cultivar & 1 & 6 & 265.73 & $<0.001$ \\
Field & 1 & 20 & 0.07 & 0.975 \\
Treatment $\times$ cultivar & 3 & 16 & 2.95 & 0.064 \\
Treatment $\times$ field & 3 & 20 & 0.97 & 0.336 \\
Field $\times$ cultivar & 1 & 20 & 1.62 & 0.216 \\
Treatment $\times$ field $\times$ & 3 & & & \\
$\quad$ cultivar & & & & \\
\hline
\end{tabular}

a Data were transformed prior to statistical tests using either the $\ln$ transformation $\left(\mathrm{EC}_{50}\right)$ or the arcsine square root transformation (G143A frequency). 
collected from the moderately resistant cultivar as compared with the susceptible cultivar. This result is consistent with previous studies of $Z$. tritici and resistance to the fungicide cyproconazole. In their continental-scale sampling of $Z$. tritici, Yang et al. (2013) found increased virulence both for isolates with fungicide resistance and for isolates collected from a quantitatively resistant cultivar. They suggested that this was compatible with selection for a common detoxification mechanism or for increased expression of broad-spectrum efflux pumps. Also, an earlier study of western Oregon populations of Z. tritici indicated that isolates collected from an unsprayed,
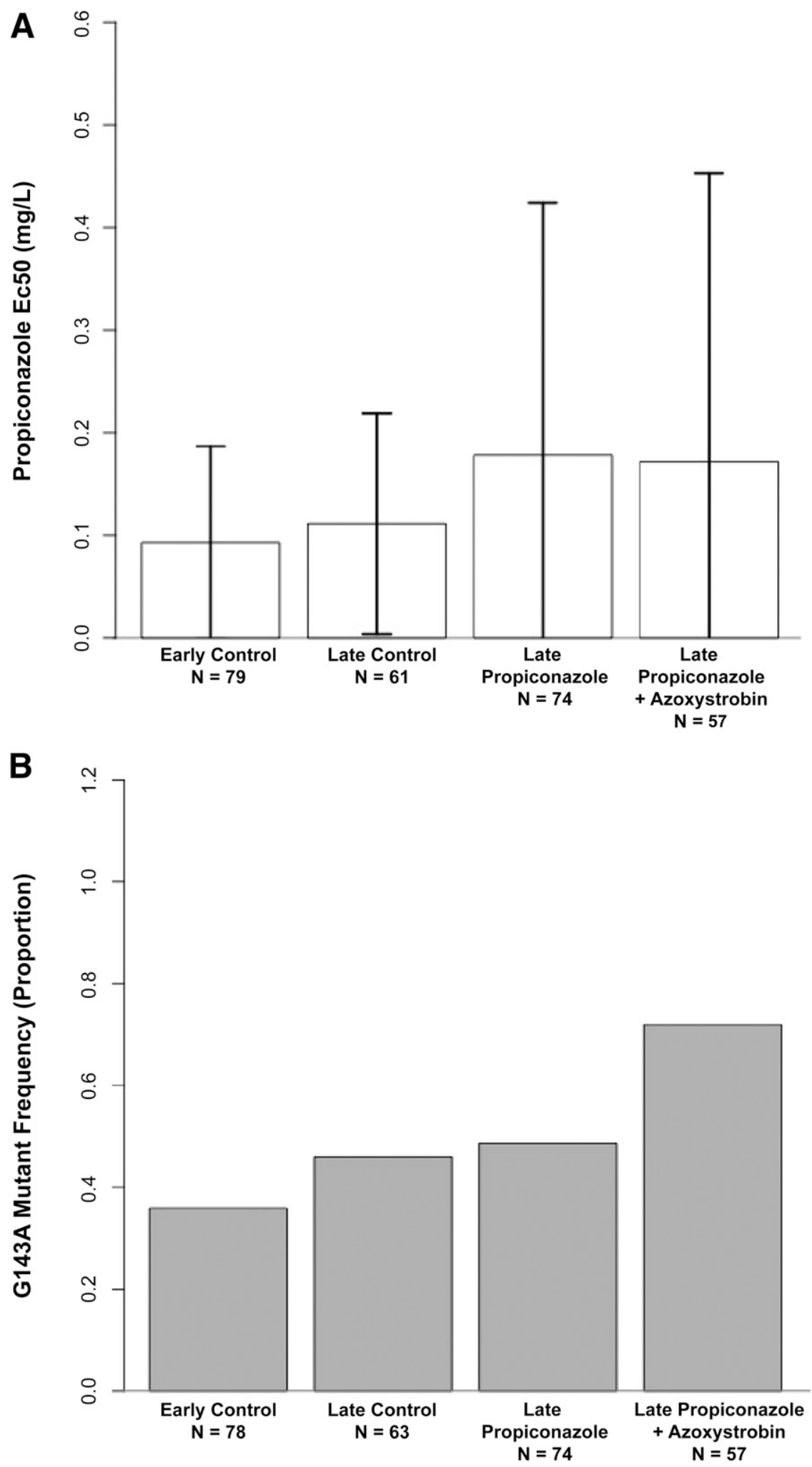

Fig. 3. A, Mean propiconazole concentration required to reduce pathogen growth by $50 \%\left(\mathrm{EC}_{50}\right)$ values of Zymoseptoria tritici isolates and $\mathrm{B}$, overall proportions of Z. tritici isolates with the G143A mutation (G143A mutant frequency) calculated across all experimental wheat plots in two locations in western Oregon in 2012: Hyslop Farm (Benton County) and North Valley Farm (Washington County). Fungicide applications (either propiconazole or propiconazole + azoxystrobin) were made twice on treatment plots, once in March and again in May 2012. "Early" in the x-axis legend refers to isolates collected 14 to 15 April 2012 and "Late" refers to collections made during 27 to 29 June 2012 . Error bars represent standard deviations. 
moderately resistant cultivar were more tolerant to cyproconazole than were isolates collected from an unsprayed, susceptible cultivar (Zhan et al. 2006). In our study, however, we found no significant effect of cultivar on resistance to propiconazole.

As in Europe (Cools and Fraaije 2013; Fraaije et al. 2012), selection for resistance to QoI fungicides has increased vulnerability of wheat to $Z$. tritici in western Oregon unless alternative control strategies are employed. Similar patterns would be expected in other North American locations in which fungicide use has been frequent. Indeed, results of this study are suggestive of this trend on a local scale, because both G143A mutation frequencies and propiconazole $\mathrm{EC}_{50}$ values were higher at NVF, which is in the northern region of the Willamette Valley where fungicide use is heavier, compared with HF, an experiment farm in the southern portion of the Willamette Valley where fungicide use is less common (Estep et al. 2013) (M. Flowers, N. P. Anderson, and C. C. Mundt, personal observation). Thus, approaches to maintaining effectiveness of QoI, DMI, and SDHI fungicides are crucial for successful long-term management of STB. Such approaches include using mixtures and alternation of fungicides with different modes of action, adjusting fungicide dosage, and reducing the number of fungicide applications (van den Bosch et al. 2014). Reducing the number of fungicide applications can be practically attained through practices such as disease forecasting and growing resistant cultivars, though effectiveness of the latter approach could be at least partially diminished through coselection between virulence and fungicide resistance (Yang et al. 2013; Zhan et al. 2006). In western Oregon, development of fungicide resistance in $Z$. tritici was accelerated by increased fungicide applications used to control new, aggressive populations of wheat stripe rust, demonstrating the importance of considering entire cropping systems when attempting to manage fungicide resistance to a given pathogen. Thus, future approaches to managing $Z$. tritici fungicide resistance in western Oregon will include choosing specific fungicides and fungicide mixtures based on levels of the two diseases at different growth stages of the crop, while accounting for resistance spectra of the pathogens to available fungicides.

\section{Acknowledgments}

We thank P. Brunner, B. A. McDonald, S. F. F. Torriani, and M. Zala of ETH Zurich for logistical support and providing facilities for collecting molecular data; the Genetic Diversity Center of ETH Zurich for funding molecular data collection; and E. Sykes of Oregon State University for assistance with leaf collections and fungal isolate preparation. L. Hayes was supported by varietal royalty funds from the Oregon State University Wheat Breeding Program.

\section{Literature Cited}

Bearchell, S. J., Fraaije, B. A., Shaw, M. W., and Fitt, B. D. L. 2005. Wheat archive links long-term fungal population dynamics to air pollution. Proc. Natl. Acad. Sci. USA 102:5438-5442.

Berry, P. M., Kindred, D. R., and Paveley, N. D. 2008. Quantifying the effects of fungicides and disease resistance on greenhouse gas emissions associated with wheat production. Plant Pathol. 57:1000-1008.

Beyer, M., Kiesner, F., Verreet, J.-A., and Klink, H. 2011. Fungicide sensitivity of Septoria tritici isolates is affected by an interaction between fungicidal mode of action and time. J. Plant Pathol. 93:S1.7-S1.13.

Brent, K. J., and Hollomon, D. W. 2007. Fungicide Resistance in Crop Pathogens: How Can It Be Managed? FRAC Monogr. No. 1 (second, revised edition). Fungicide Resistance Action Committee 2007, CropLife International, Brussels.

Brunner, P. C., Stefanato, F. L., and McDonald, B. A. 2008. Evolution of the CYP51 gene in Mycosphaerella graminicola: Evidence for intragenic combination and selective replacement. Mol. Plant Pathol. 9:305-316.

Chen, R.-S., Boeger, J. M., and McDonald, B. A. 1994. Genetic stability in a population of a plant pathogenic fungus over time. Mol. Ecol. 3:209-218.

Cools, H. J., and Fraaije, B. A. 2013. Update on mechanisms of azole resistance in Mycosphaerella graminicola and implications for future control. Pest Manage. Sci. 69:150-155.

Cooper, J., and Dobson, H. 2007. The benefits of pesticides to mankind and the environment. Crop Prot. 26:1337-1348.

Deising, H. B., Reimann, S., and Pascholati, S. F. 2008. Mechanisms and significance of fungicide resistance. Braz. J. Microbiol. 39:286-295.

Edwards-Jones, G. 2008. Do benefits accrue to 'pest control' or 'pesticides?': A comment on Cooper and Dobson. Crop Prot. 27:965-967.

Estep, L. K., Torriani, S. F. F., Zala, M., Anderson, N. P., Flowers, M. D., McDonald, B. A., Mundt, C. C., and Brunner, P. C. 2015. Emergence and early evolution of fungicide resistance in North American populations of Zymoseptoria tritici. Plant Pathol. 64:961-971.

Estep, L. K., Zala, M., Anderson, N. P., Sackett, K. E., Flowers, M., McDonald, B. A., and Mundt, C. C. 2013. First report of resistance to QoI fungicides in North American populations of Zymoseptoria tritici, causal agent of Septoria tritici blotch of wheat. Plant Dis. 97:1511.

Federer, W. T., and King, F. 2007. Variations on Split Plot and Split Block Experiment Designs. John Wiley \& Sons, Inc., Hoboken, NJ.

Fraaije, B. A., Bayon, C., Atkins, S., Cools, H. J., Lucas, J. A., and Fraaije, M. W. 2012 Risk assessment studies on succinate dehydrogenase inhibitors, the new weapons in the battle to control Septoria leaf blotch in wheat. Mol. Plant Pathol. 13:263-275.

Fraaije, B. A., Cools, H. J., Fountaine, J., Lovell, D. J., Motteram, J., West, J. S and Lucas, J. A. 2005. Role of ascospores in further spread of QoI-resistant cytochrome b alleles (G143A) in field populations of Mycosphaerella graminicola. Phytopathology 95:933-941.

Gisi, U., Sierotzki, H., Cook, A., and McCaffery, A. 2002. Mechanisms influencing the evolution of resistance to Qo inhibitor fungicides. Pest Manage. Sci. 58:859-867.

Hewitt, H. G. 1998. Fungicides in Crop Protection. CAB International, Wallingford, UK.

Hovmøller, M. S., Yahyaoui, A. H., Milus, E. A., and Justesen, A. F. 2008. Rapid global spread of two aggressive strains of a wheat rust fungus. Mol. Ecol. 17:3818-3826.

King, J. E., Cook, R. J., and Melville, S. C. 1983. A review of Septoria diseases of wheat and barley. Ann. Appl. Biol. 103:345-373.

Ma, Z., and Michailides, T. J. 2005. Advances in understanding molecular mechanisms of fungicide resistance and molecular detection of resistant genotypes in phytopathogenic fungi. Crop Prot. 24:853-863.

McCartney, C., Mercer, P. C., Cooke, L. R., and Fraaije, B. A. 2007. Effects of strobilurin-based programme on disease control, green leaf area, yield and development of fungicide-resistance in Mycosphaerella graminicola in Northern Ireland. Crop Prot. 26:1272-1280.

McDonald, B. A., and Martinez, J. P. 1990. DNA restriction fragment length polymorphisms among Mycosphaerella graminicola (anamorph Septoria tritici) isolates collected from a single wheat field. Phytopathology 80:1368-1373.

Milus, E. A., Kristensen, K., and Hovmøller, M. S. 2009. Evidence for increased aggressiveness in a recent widespread strain of Puccinia striiformis f. sp. tritici causing stripe rust of wheat. Phytopathology 99:89-94.

Morton, V., and Staub, T. 2008. A Short History of Fungicides. Online publication. APSnet Features, doi:10.1094/APSnetFeature-2008-0308

Mundt, C. C., Hoffer, M. E., Ahmed, H. U., Coakley, S. M., DiLeone, J. A., and Cowger, C. 1999. Population genetics and host resistance. Pages 115-130 in: Septoria on Cereals: A Study of Pathosystems. J. A. Lucas, P. Bowyer, and H. M. Anderson, eds. CAB International, Wallingford, UK.

NSF Center for Integrated Pest Management. 1999. Crop Profile for Wheat in Oregon Online publication. http://www.ipmcenters.org/cropprofiles/docs/orwheat.pdf

Pimentel, D. 2005. Environmental and economic costs of the application of pesticides primarily in the United States. Environ. Dev. Sustain. 7:229-252.

Pscheidt, J. W., and Ocamb, C. M., eds. 2000. Pacific Northwest Plant Disease Management Handbook. Oregon State University, Corvallis.

R Core Team. 2013. R: A Language and Environment for Statistical Computing. R Foundation for Statistical Computing, Vienna. http://www.R-project.org/

Ragsdale, N. N., and Sisler, H. D. 1994. Social and political implications of managing plant diseases with decreased availability of fungicides in the United States. Annu. Rev. Phytopathol. 32:545-557.

Russell, P. E. 2005. A century of fungicide evolution. J. Agric. Sci. 143:11-25.

SAS Institute. 2008. SAS Version 9.2. SAS Institute, Cary, NC.

Sierotzki, H., and Scalliet, G. 2013. A review of current knowledge of resistance aspects for the next-generation succinate dehydrogenase inhibitor fungicides. Phytopathology 103:880-887.

Tilman, D., Fargione, J., Wolff, B., D'Antonio, C., Dobson, A., Howarth, R., Schindler, D., Schlesinger, W. H., Simberloff, D., and Swackhamer, D. 2001. Forecasting agriculturally driven global environmental change. Science 292:281-284.

Torriani, S. F. F., Brunner, P. C., McDonald, B. A., and Sierotzki, H. 2009. Qol resistance emerged independently at least 4 times in European populations of Mycosphaerella graminicola. Pest Manage. Sci. 65:155-162.

Torriani, S. F. F., Goodwin, S. B., Kema, G. H. J., Pandilinan, J. L., and McDonald, B. A. 2008. Intraspecific comparison and annotation of two complete mitochondrial genome sequences from the plant pathogenic fungus Mycosphaerella graminicola. Fungal Genet. Biol. 45:628-637.

Urech, P. A., Staub, T., and Voss, G. 1997. Review: Resistance as a concomitant of modern crop protection. Pestic. Sci. 51:227-234.

USDA NASS. 2013. 2012-2013 Oregon Agriculture \& Fisheries Statistics. USDA National Agricultural Statistics Service, Portland, OR.

van den Bosch, F., Oliver, R., van den Berg, F., and Paveley, N. 2014. Governing principles can guide fungicide-resistance management tactics. Annu. Rev. Phytopathol. 52:175-195.

Wilson, C., and Tisdell, C. 2001. Why farmers continue to use pesticides despite Environmental, health and sustainability costs. Ecol. Econ. 39:449-462.

Yang, L., Gao, F., Shang, L., Zhan, J., and McDonald, B. A. 2013. Association between virulence and triazole tolerance in the phytopathogenic fungus Mycosphaerella graminicola. PLoS One 8:e59568.

Zhan, J., Stefanato, F., and McDonald, B. A. 2006. Selection for increased cyproconazole tolerance in Mycosphaerella graminicola through local adaptation and in response to host resistance. Mol. Plant Pathol. 7:259-268. 